\title{
Contribution of CD3 $\varepsilon$ Epitope and Oxidative Type of Copper-Zinc Superoxide Dismutase to the Degeneration Processes of Cerebellar Purkinje Cells in Patients with Multiple System Atrophy-Cerebellar Type (MSA-C: Olivopontocerebellar Atrophy, OPCA): An Immunohistochemical Study
}

\author{
Masako Kato $^{1 * \#, ~ S h i n s u k e ~ K a t o ~}{ }^{2 \#}$, Kiyota Kato $^{3}$, Kazuhiko Hayashi ${ }^{1}$ \\ ${ }^{1}$ Division of Molecular Pathology, Department of Pathology, Tottori University Faculty of Medicine, Yonago, Japan \\ ${ }^{2}$ Division of Neuropathology, Department of Pathology, Tottori University Faculty of Medicine, Yonago, Japan \\ ${ }^{3}$ School of Medicine, Hiroshima University, Hiroshima, Japan \\ Email: *makato@grape.med.tottori-u.ac.jp
}

How to cite this paper: Kato, M., Kato, S. Kato, K. and Hayashi, K. (2016) Contribution of CD3 $\varepsilon$ Epitope and Oxidative Type of Copper-Zinc Superoxide Dismutase to the Degeneration Processes of Cerebellar Purkinje Cells in Patients with Multiple System Atrophy-Cerebellar Type (MSA-C: Olivopontocerebellar Atrophy, OPCA): An Immunohistochemical Study. World Journal of Neuroscience, 6, 310-324. http://dx.doi.org/10.4236/wjns.2016.64034

Received: October 18, 2016 Accepted: November 21, 2016 Published: November 24, 2016

Copyright $\odot 2016$ by authors and Scientific Research Publishing Inc. This work is licensed under the Creative Commons Attribution International License (CC BY 4.0).

http://creativecommons.org/licenses/by/4.0/

\section{Abstract}

Objective: This study aimed to investigate the contribution of CD3 epsilon $(\varepsilon)$ epitope and oxidative type of copper-zinc superoxide dismutase to the degeneration processes of cerebellar Purkinje cells in patients with Multiple System Atrophy-Cerebellar type (MSA-C). Methods: This retrospective study was carried out on autopsy specimens of 17 patients with sporadic MSA-C and 10 normal individuals. Paraffin sections of autopsied cerebella and pontes were immunostained with polyclonal antibodies against CD3 $\varepsilon$ epitope and oxidative modification to cysteine sulfonic acid of cys $^{111}$ in human copper-zinc superoxide dismutase (Ox-SOD1). With respect to the areas of CD3- $\varepsilon$-epitope expression, the immunohistochemical study and the quantitative statistical analysis between the areas of CD3- $\varepsilon$-epitope expression in the surviving Purkinje cells of MSA-C patients and their disease duration were performed. Results: The cell bodies and dendritic arborization including primary, secondary, and tertiary dendrites of normal Purkinje cells were intensely immunostained by the antibody against CD3 $\varepsilon$ epitope. Both the immunohistochemical study and the quantitative statistical analysis revealed that the areas positive for CD3 $\varepsilon$ epitope disappeared in the order from tertiary dendrites, secondary dendrites, primary dendrites toward

\section{(c) (i) Open Access}


the cell bodies, along with the disease progression. In addition, Glial Cytoplasmic Inclusions (GCIs) and Neuronal Cytoplasmic Inclusions (NCIs) were strongly positive for CD3 $\varepsilon$ epitope. The surviving Purkinje cells in MSA-C showed immunostaining by the anti-Ox-SOD1 antibody, although normal Purkinje cells did not. Conclusion: Based on the oxidative stress that the surviving Purkinje cells in MSA-C express Ox-SOD1, the functions of morphogenesis and morphological maintenance related to CD3- $\varepsilon$-epitope expression of the MSA-C Purkinje cells are impaired from the peripheral dendrites toward the cell bodies as the center of the Purkinje cell system. In addition, GCIs and NCIs that are pathological hallmarks of MSA also intensely express $\mathrm{CD} 3 \varepsilon$ epitope.

\section{Keywords}

CD3 Epsilon ( $\varepsilon$ ) Epitope, Glial Cytoplasmic Inclusion (GCI), Multiple System Atrophy, Oxidative Stress, Purkinje Cell

\section{Introduction}

The pathogenesis of Multiple System Atrophy (MSA) currently remains unknown. MSA is a single entity that includes olivopontocerebellar atrophy (OPCA), striatonigral degeneration (SND) and Shy-Drager syndrome [1]. One type of MSA is characterized by damage mainly to cerebellum, especially cerebellar Purkinje cells, and this type is designated as Multiple System Atrophy-Cerebellar type (MSA-C) [2]. Neuropathological findings in cases of MSA-C show the loss of Purkinje cells in the cerebellar cortex, and not only do their numbers decrease, but abnormal morphological changes of Purkinje cells also occur as part of the process of degeneration under MSA-C stress [1]. Golgi impregnation method has often been used in the study of morphological alterations of cerebellar Purkinje cells from earlier studies [2]. However, Golgi impregnation method itself includes the complexity of staining and its lack of accurate reproducibility. For example, there is the fact that not all normal cerebellar Purkinje cells are reliably stained by Golgi impregnation method: some normal Purkinje cells are stained by Golgi impregnation method, but others are not. Although there must be some molecular difference between Purkinje cells that are positive and negative for Golgi staining, as yet this difference is incompletely understood. To date, a number of molecular markers for the morphological and functional analysis of cerebellar Purkinje cells have already been reported [3]-[13].

Cluster of Differentiation 3 (CD3) is a membrane protein of $\mathrm{T}$ lymphocytes that is generally well known [14] [15]. We reported that human normal cerebellar Purkinje cells of fetus at 21 weeks gestation became positive for $\mathrm{CD} 3 \varepsilon$ epitope for the first time. The CD3- $\varepsilon$-epitope positive area of Purkinje cells expanded from soma, through the primary dendrites, the secondary dendrites to the tertiary dendrites during the normal development of human cerebellum. The normal cerebellar Purkinje cells at one year and six months of age revealed almost the same immunohistochemical expression pat- 
tern of cell bodies and dendritic arborization seen in normal adults. Based on the facts that expression of CD3 $\varepsilon$ epitope in human normal cerebellar Purkinje cells continued on from the gestation age of 21 weeks to adulthood and that the expression area of CD3 $\varepsilon$ epitope extended in the order of the soma, the primary dendrites, the secondary dendrites, and the tertiary dendrites [16], we are convinced that CD3 $\varepsilon$ epitope in human cerebellar Purkinje cells could be involved with morphogenesis and morphological maintenance of normal development stage of Purkinje cells [16] [17].

In MSA-C, on the other hand, cerebellar Purkinje cells exhibit morphopathological degeneration and eventually disappearing due to cell death as a result of MSA stress of unknown origin. We have analyzed the process of degeneration of cerebellar Purkinje cells in MSA-C from the standpoint of morphodegeneration by using antibody to the $\mathrm{CD} 3 \varepsilon$ epitope. We have also investigated whether or not oxidative stress is directly implicated in the pathogenesis of MSA-C as one of the MSA-C stresses that induce Purkinje cell death by using antibody against oxidized superoxide dismutase 1 .

\section{Materials and Methods}

This retrospective study was carried out on brain tissues from 17 patients with sporadic MSA-C. The main clinical characteristics in MSA-C patients were summarized in Table 1. None of the patients had been placed on respirators. Autopsy specimens of 10 individuals ( 4 males and 6 female; aged 43 to 74 years) were also examined as normal cases: all 10 cases showed no neurological sign. All cases were examined within postmortem 24 hours. Formalin-fixed, paraffin embedded cerebella and pontes were used. Several serial $6 \mu \mathrm{m}$ sections were prepared from each of the specimens. All paraffin sections were the sagittal sections which intersected cerebellar folia at an angle of 90 degrees. One section was stained with hematoxylin and eosin (H\&E) and others were used for immunohistochemical analyses. The following primary antibodies were used for the immunohistochemical study: the polyclonal antibody against CD3 $\varepsilon$ epitope (Dako, Glostrup, Denmark, 1:100 dilution) and the polyclonal antibody against oxidative modification to cysteine sulfonic acid of $\mathrm{cys}^{111}$ in human copper-zinc superoxide dismutase (Ox-SOD1, 1:1000 dilution) [18]. The avidin-biotin-immunoperoxidase complex (ABC) method was used for epitope detection. Briefly, the paraffin sections were deparaffinized and endogenous peroxidase was quenched by incubation for $30 \mathrm{~min}$ with $0.3 \%$ $\mathrm{H}_{2} \mathrm{O}_{2}$. Normal sera homologous with the secondary antibodies were used as blocking reagents. Sections were incubated with primary antibodies overnight at $4^{\circ} \mathrm{C}$; sections incubated with PBS were used as controls. Visualization of bound antibodies was done with the respective Vectastain ABC kit (Vector Laboratories, Burlingame, Calif, USA) following the manufacturer's protocol. The final chromogen was 3, 3'-diami- nobenzidine tetrahydrochloride. The protocols were approved by the Ethics Committee in Tottori University Faculty of Medicine (No. 1246).

Quantitative analysis and classification of CD 3-E-epitope expression pattern in cerebellar Purkinje cells of normal controls and MSA-C patients. All of the sections immunostained by the antibody against $\mathrm{CD} 3 \varepsilon$ epitope were observed under a light mi- 
Table 1. Clinical characteristics and CD3- $\varepsilon$-epitope staining score of the patients with multiple system atrophy-cerebellar type.

\begin{tabular}{|c|c|c|c|c|c|}
\hline $\begin{array}{l}\text { No. of } \\
\text { case }\end{array}$ & $\begin{array}{c}\text { Age } \\
\text { (years) }\end{array}$ & Gender & $\begin{array}{c}\text { Disease } \\
\text { duration (years) }\end{array}$ & Cause of death & $\begin{array}{l}\text { CD3- } \varepsilon \text {-epitope staining score } \\
\text { (mean } \pm \text { standard error) }\end{array}$ \\
\hline 1 & 41 & $\mathrm{~F}$ & 1.33 & pneumonia & $2.83 \pm 0.13$ \\
\hline 2 & 60 & $\mathrm{~F}$ & 3 & pneumonia & $3.07 \pm 0.11$ \\
\hline 3 & 66 & M & 3 & pneumonia & $2.50 \pm 0.19$ \\
\hline 4 & 33 & M & 3 & pneumonia & $2.23 \pm 0.16$ \\
\hline 5 & 71 & $\mathrm{~F}$ & 3 & pneumonia & $2.83 \pm 0.17$ \\
\hline 6 & 68 & M & 4 & pneumonia & $1.40 \pm 0.16$ \\
\hline 7 & 66 & M & 5 & pneumonia & $1.97 \pm 0.18$ \\
\hline 8 & 68 & M & 7 & pneumonia & $1.67 \pm 0.22$ \\
\hline 9 & 71 & M & 7 & pneumonia & $2.43 \pm 0.21$ \\
\hline 10 & 48 & $\mathrm{~F}$ & 8 & unknown & $2.43 \pm 0.20$ \\
\hline 11 & 71 & $\mathrm{~F}$ & 8 & sudden death & $1.23 \pm 0.14$ \\
\hline 12 & 57 & M & 9 & pneumonia & $1.97 \pm 0.18$ \\
\hline 13 & 57 & $\mathrm{~F}$ & 9 & pneumonia & $2.00 \pm 0.14$ \\
\hline 14 & 61 & M & 9 & heart failure & $1.17 \pm 0.11$ \\
\hline 15 & 65 & $\mathrm{~F}$ & 10 & pneumonia & $2.03 \pm 0.12$ \\
\hline 16 & 74 & M & 12 & pneumonia & $1.47 \pm 0.13$ \\
\hline 17 & 62 & $\mathrm{~F}$ & 23 & $\begin{array}{c}\text { urinary } \\
\text { infection }\end{array}$ & $0.83 \pm 0.13$ \\
\hline
\end{tabular}

M: male, F: female.

croscope (BX41: Olympus Corp., Tokyo, Japan) equipped with a 3CCD digital color camera system (FX380: Olympus Corp.). Photographs of the cerebellar Purkinje cells in each stained section were taken and the images were analyzed using image analysis software (FLVFS-LS Ver. 1.12: Olympus Corp.). All Purkinje cells were classified into five immunostaining patterns as follows (Table 2): Type $1=$ the CD3 $\varepsilon$ epitope was not expressed in the Purkinje cell body or any of the dendritic arborization, whether primary, secondary, or tertiary dendrites; Type $2=$ the Purkinje cell body exhibited a positive reaction to immunostaining for the $\mathrm{CD} 3 \varepsilon$ epitope. However, the primary, secondary, and tertiary dendrites were negative; Type $3=$ the Purkinje cell body and primary dendrites exhibited a positive reaction to immunostaining for the CD3 $\varepsilon$ epitope. However, the secondary and tertiary dendrites were negative; Type $4=$ the Purkinje cell body as well as primary and secondary dendrites exhibited a positive reaction to anti-CD3 $\varepsilon$-epitope antibody. However, the tertiary dendrites were negative; Type $5=$ the Purkinje cell body and all the dendritic processes, whether primary, secondary, or tertiary dendrites, exhibited a positive reaction to anti-CD3 $\varepsilon$ epitope antibody. The CD3 $\varepsilon$ epitope staining patterns of cerebellar Purkinje cells from Type 1 to Type 5 were scored 
Table 2. Classification of CD3- $\varepsilon$-epitope immunostaining patterns and staining score.

\begin{tabular}{ccc}
\hline Type & CD3- $\varepsilon$-epitope positive area of one Purkinje cell & Staining score \\
\hline 1 & No positive-staining area & 0 \\
2 & Cell body & 1 \\
3 & Cell body and the primary dendrite & 2 \\
4 & Cell body, the primary and the secondary dendrites \\
5 & Cell body, the primary, the secondary and the tertiary dendrites & 4 \\
\hline
\end{tabular}

as follows: Type 1 scored 0; Type 2 scored 1; Type 3 scored 2; Type 4 scored 3; and Type 5 scored 4 . The CD3- $\varepsilon$-epitope staining patterns of individual cerebellar Purkinje cells from all normal control cases and all MSA-C patients tested were classified and scored for quantitative analysis. In order to make a quantitative analysis of the CD3- $\varepsilon$-epitope staining patterns of cerebellar Purkinje cells in normal control cases and MSA-C patients, 30 individual Purkinje cells with an identifiable nucleus in the cell body were counted, and the CD3- $\varepsilon$-epitope staining patterns of the individual cells were classified and scored. The mean score for these 30 cerebellar Purkinje cells in each patient was defined as that patient's CD3- $\varepsilon$-epitope staining score. We analyzed the correlation between the CD3- $\varepsilon$-epitope staining score $(Y)$ for each MSA-C patient and their disease duration $(X)$. Liner regression was done using Regression Program and its Pearson correlation coefficient calculated. Statistical analysis was performed using the program: Statistical Package for Social Sciences (SPSS: Version 20.0). All experiments were conducted as a double blind study.

\section{Results}

The Purkinje cell layer in the cerebral cortex of normal adults comprised Purkinje cells stacked in a single row. These normal cerebellar Purkinje cells showed large cell bodies and dendritic arborization. The cell bodies of Purkinje cells showed the form of the pear type. Primary and secondary dendrites are often seen, and even tertiary dendrites are sometimes observed (Figure 1(a)). During the procedures of immunostaining, when normal control tissue sections were incubated with PBS, no immunoreaction products were seen. The cell bodies, the primary dendrites, the secondary dendrites, and the tertiary dendrites of normal cerebellar Purkinje cells in adults strongly express CD3 $\varepsilon$ epitope (Figure 1(b)). The nuclei of normal Purkinje cells are negative. The CD3- $\mathcal{E}$-epitope staining score for Purkinje cells in normal adults was 4.0.

The cerebellar Purkinje cell count was lower in MSA-C patients with disease duration of $\leq 3$ years than in normal individuals. Although the residual Purkinje cells in MSA-C patients were atrophic and the cell body size of the Purkinje cells slightly decreased in comparison with normal Purkinje cells, the soma shape of the Purkinje cells still kept the form of the pear type. Primary and secondary dendrites were often seen (Figure $1(\mathrm{c})$ ). In the CD3- $\varepsilon$-epitope immunostaining, the cell bodies, the primary dendrites, and the secondary dendrites of the residual Purkinje cells expressed CD $3 \varepsilon$ epi 

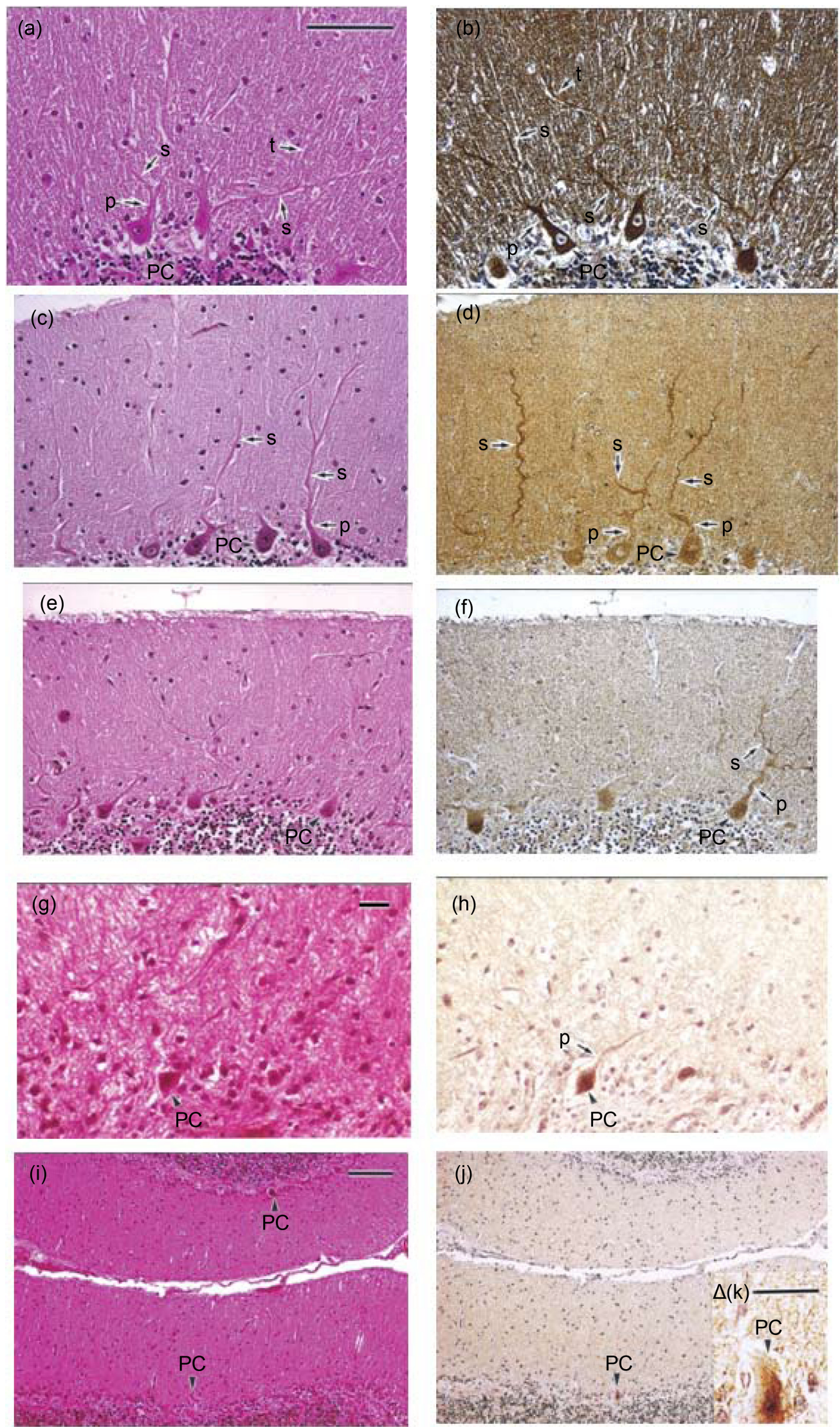
Figure 1. Hematoxylin and eosin (H\&E) staining and CD3- $\varepsilon$-epitope immunostaining of human cerebellar Purkinje cells from a normal individual and patients with multiple system atrophy-cerebellar type (MSA-C: olivopontocerebellar atrophy: OPCA). (a). Normal cerebellar Purkinje cells of a 67-year-old female stained with H\&E staining. The cell bodies of Purkinje cells show the form of the pear type (arrowhead and PC). Primary (arrow and p) and secondary (arrow and s) dendrites are often seen, and even tertiary (arrow and $\mathrm{t}$ ) dendrites are sometimes observed. (b). Serial CD3-E-epitope immunostained section of H\&E staining (Figure 1(a)), the cell bodies (arrowhead and PC), the primary dendrites (arrow and p), the secondary dendrites (arrow and s), and the tertiary dendrites (arrow and t) of normal cerebellar Purkinje cells strongly express CD3 $\varepsilon$ epitope. The nuclei of Purkinje cells are negative. (c). H\&E staining in a patient with MSA-C after a clinical course of 3 years. Residual viable Purkinje cells (arrowhead and PC) are observed. Although these residual Purkinje cells are atrophic and the cell body size of the Purkinje cells slightly decreases in comparison with normal Purkinje cells (Figure 1(a)), the soma shape of the Purkinje cells still keeps the form of the pear type. Primary (arrow and p) and secondary (arrow and s) dendrites are often seen. (d). Serial CD3- $\varepsilon$-epitope immunostained section of H\&E staining (Figure $1(\mathrm{c})$ ). The cell bodies (arrowhead and PC), the primary dendrites (arrow and p), and the secondary dendrites (arrow and s) of the residual Purkinje cells express CD3 $\varepsilon$ epitope. Parts of the dendrites present the coiled form. (e). H\&E staining in a patient with MSA-C after a clinical course of 5 years. The number of the remaining Purkinje cells (arrowhead and PC) decreases compared with the MSA-C patient after a clinical course of 3 years (Figure $1(\mathrm{c})$ ). The cell bodies of Purkinje cells become atrophied. (f). Serial CD3-E-epitope immunostained section of H\&E staining (Figure 1(e)). The cell body (arrowhead and PC), the primary dendrite (arrow and p), and the secondary dendrites (arrow and s) of one remaining Purkinje cell is positive for CD3 $\varepsilon$ epitope. However, the secondary dendrites of the other Purkinje cells do not express CD3 $\varepsilon$ epitope. (g). H\&E staining in a patient with MSA-C after a clinical course of 9 years. The number of the surviving Purkinje cells decreases compared with the MSA-C patient after a clinical course of 5 years (Figure 1(e)). The cell body of the surviving Purkinje cell becomes atrophied and the shape of the cell body of the Purkinje cell shows a triangle-like shape (arrowhead and PC). (h). Serial CD3- $\varepsilon$-epitope immunostained section of H\&E staining (Figure 1(g)). The diamondshaped cell body (arrowhead and PC) of one surviving Purkinje cell express CD3 $\varepsilon$ epitope, and the primary dendrite (arrow and p) of the Purkinje cell weekly express CD3 $\varepsilon$ epitope. (i). H\&E staining in a patient with MSA-C after a clinical course of 23 years. The number of the surviving Purkinje cells decreases severely and only two surviving Purkinje cells (arrowhead and PC) can be seen. (j). Serial CD3- -epitope immunostained section of H\&E staining (Figure 1(i)). The only one surviving Purkinje cell (arrowhead and PC) expresses CD3 $\varepsilon$ epitope, and the dendritic arborization of the Purkinje cell does not express CD3 $\varepsilon$ epitope. (k). A higher magnification of the Purkinje cell indicated by arrow and PC in Figure 1(j). The cell body of the Purkinje cell becomes atrophied severely (arrowhead and PC). Figures 1(a)-(f) (same magnification as Figure 1(a)): Scale bar $=100 \mu \mathrm{m}, 1 \mathrm{G}$ and $1 \mathrm{H}$ (same magnification as Figure 1(g)): Scale bar $=20 \mu \mathrm{m}$, Figure 1(i) and Figure 1(j) (same magnification as Figure 1(i)): Scale bar $=100 \mu \mathrm{m}$.

tope (Figure 1(d)). Parts of the dendrites presented the coiled form as one factor of morphopathological degeneration. Most of the tertiary dendrites were negative for $\mathrm{CD} 3 \varepsilon$ epitope. The CD3- $\varepsilon$-epitope staining score in MSA-C patients with a disease duration of $\leq 3$ years was lower, ranging from $3.07 \pm 0.11$ to $2.23 \pm 0.16$ (Table 1 ). Related to the immunohistochemical finding that most of the tertiary dendrites of the residual Purkinje cells were negative for the CD3 $\varepsilon$ epitope, the width of the molecular layer was narrower in MSA-C patients with the disease duration of $\leq 3$ years than that in normal adults.

The number of the remaining Purkinje cells of the MSA-C patients with the clinical 
courses of 4 - 7 years decreased in comparison with the MSA-C patients with the clinical courses of $\leq 3$ years (Figure 1(e)). The cell bodies of the remaining Purkinje cells became atrophied, and the form of cell bodies showed the oval-like shape (Figure 1(e)). The cell body, the primary dendrites, and the secondary dendrites of some remaining Purkinje cells were positive for $\mathrm{CD} 3 \varepsilon$ epitope (Figure 1(f)). However, the secondary dendrites of the most of Purkinje cells did not express CD3 $\varepsilon$ epitope. For patients with the disease duration of $4-7$ years, the $\mathrm{CD} 3-\mathcal{E}$-epitope staining score ranged from $2.43 \pm$ 0.21 to $1.40 \pm 0.16$, even lower than the scores for MSA-C patients with the disease duration of $\leq 3$ years.

The number of the surviving Purkinje cells of the MSA-C patients with the clinical courses of $8-12$ years (Figure $1(\mathrm{~g})$ ) decreased compared with that of the MSA-C patients with the clinical courses of $4-7$ years. The cell bodies of the surviving Purkinje cells became atrophied and the shape of the cell bodies of the surviving Purkinje cells showed the diamond-like or triangle-like shape. In the CD3-E-epitope immunostaining, the atrophied cell bodies of the surviving Purkinje cells expressed CD3 $\varepsilon$ epitope, and the primary dendrites of the Purkinje cells weekly expressed CD3 $\varepsilon$ epitope (Figure 1(h)). The CD3- $\varepsilon$-epitope staining score in MSA-C patients with the disease duration of 8 - 12 years ranged from $2.43 \pm 0.20$ to $1.17 \pm 0.11$.

The number of the surviving Purkinje cells of the patient with MSA-C after a clinical course of 23 years severely decreased (Figure 1(i)). The cell bodies of the surviving Purkinje cells exhibited severe atrophy. Only the cell bodies of the surviving Purkinje cells expressed CD3 $\varepsilon$ epitope, and the dendritic arborization of the Purkinje cells did not expresses CD3 $\varepsilon$ epitope (Figure $1(\mathrm{j})$ ). In close relation with the severe cell loss and the serious atrophy in the surviving Purkinje cells in a patient with after a clinical course of 23 years, the width of the molecular layer became very thin (Figure 1(j)).

The CD3 $\varepsilon$ epitope staining score for the MSA-C patient with a disease duration of 23 years was $0.83 \pm 0.13$.

A statistical analysis between the $\mathrm{CD} 3-\mathcal{E}$-epitope staining score and disease duration for all 17 MSA-C patients revealed that CD3- $\varepsilon$-epitope staining score $(\mathrm{Y})$ was correlated with disease duration $(X)$, with the regression line having the relation $Y=2.656-$ $0.089 X$, and the Pearson correlation coefficient $R=-0.705(p=0.002)$ (Figure 2). As disease duration increased, the CD3- $\varepsilon$-epitope staining score declined. Quantitative analysis based on statistical methods thus demonstrated that the loss of CD3- $\varepsilon$-epitope reactivity started from the tertiary dendrites, which are the peripheral dendritic processes, and gradually extended to the secondary and then the primary dendrites as the disease progressed, with its expression finally lost from the cell body. Both immunohistochemical study and quantitative statistical analysis therefore showed that the loss immunoreactivity of the CD3 $\varepsilon$ epitope started at the periphery of the dendritic arborization of Purkinje cells and proceeded toward the cell body as the center of the Purkinje cell system, along with disease progression.

Non-neuronal cytoplasmic inclusions, i.e., the glial cytoplasmic inclusions (GCIs) 


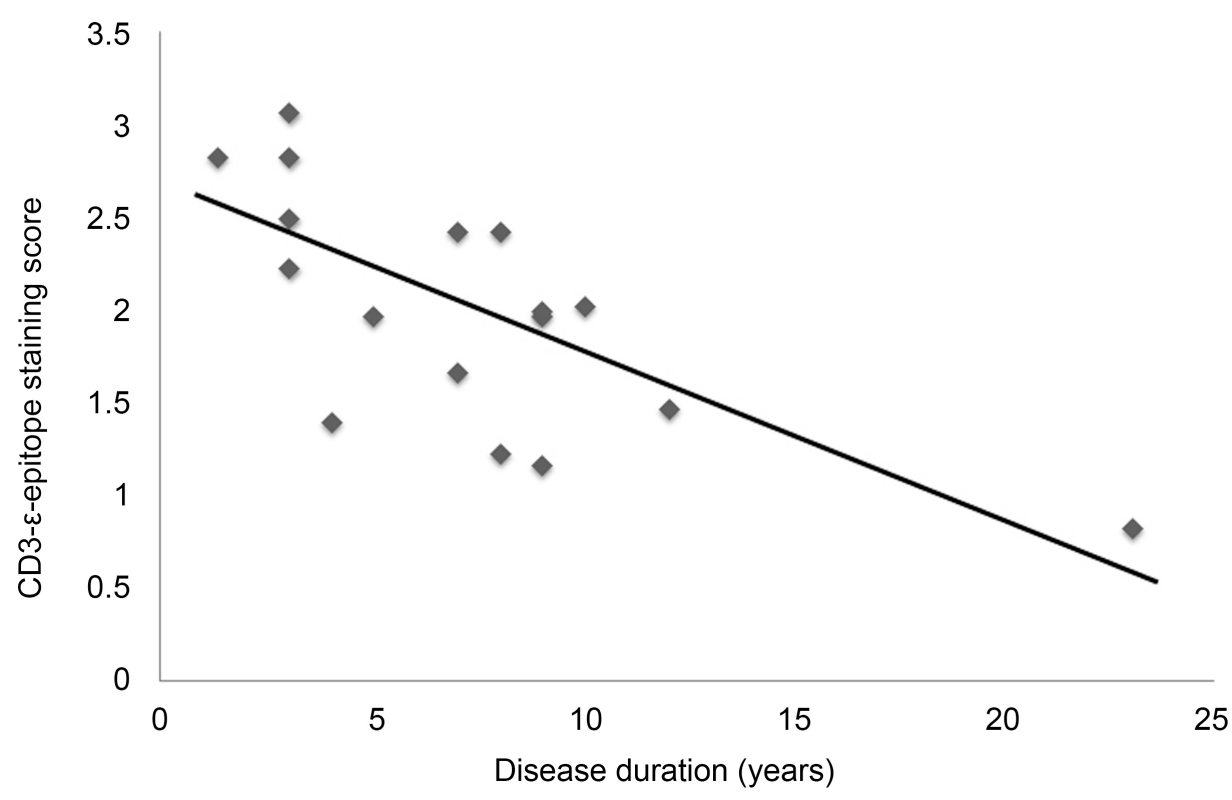

Figure 2. Correlation between CD3- $\varepsilon$-epitope staining score of Purkinje cells and disease duration of MSA-C patients. CD3- $\varepsilon$-epitope staining score $(\mathrm{Y})$ is correlated with disease duration $(X)$, with the regression line having the relation $Y=2.656-0.089 X$, and the Pearson correlation coefficient $R=-0.705(p=0.002)$.

were observed in all 17 MSA-C patients. GCIs appeared pale structure in H\&E staining (Figure 3(a)). All GCIs were strongly positive for CD3 $\varepsilon$ epitope (Figure 3(b)). In addition, the neurons of pontine nuclei had neuronal cytoplasmic inclusions (NCIs) in 6 of the 17 MSA-C patients. These NCIs were relatively demarcated and appeared pale: the nuclei were displaced to the cellular periphery in H\&E staining (Figure 3(c)). All NCIs were intensively recognized by immunostaining using antibody against CD3 $\varepsilon$ epitope (Figure 3(d)).

Purkinje cells of the normal cerebellum did not show immunostaining by the antibody for Ox-SOD1 (Figure 4(a)). By marked contrast, almost of all of the surviving Purkinje cells showed immunostaining by the anti-Ox-SOD1 antibody at varying intensities, regardless of the disease duration of 17 MSA-C patients (Figures 4(b)-(d)).

\section{Discussion}

In normal adult cerebellar Purkinje cells, positive reactivity of the CD3 $\varepsilon$ epitope was evident in all Purkinje cell bodies and their primary, secondary, and tertiary dendrites. CD3- $\varepsilon$-epitope expression in the cell membrane and cytoplasm of normal adult Purkinje cells is involved in maintaining the morphology of Purkinje cell bodies and primary, secondary, and tertiary dendrites: namely, one mechanism in maintaining Purkinje cell bodies and the arborization of their dendritic processes in normal adults is the function of the CD3 $\varepsilon$ epitope [16] [17].

Our results of immunohistochemical study and quantitative statistical analysis between the areas of CD3- $\varepsilon$-epitope expression in the residual Purkinje cells of MSA-C 

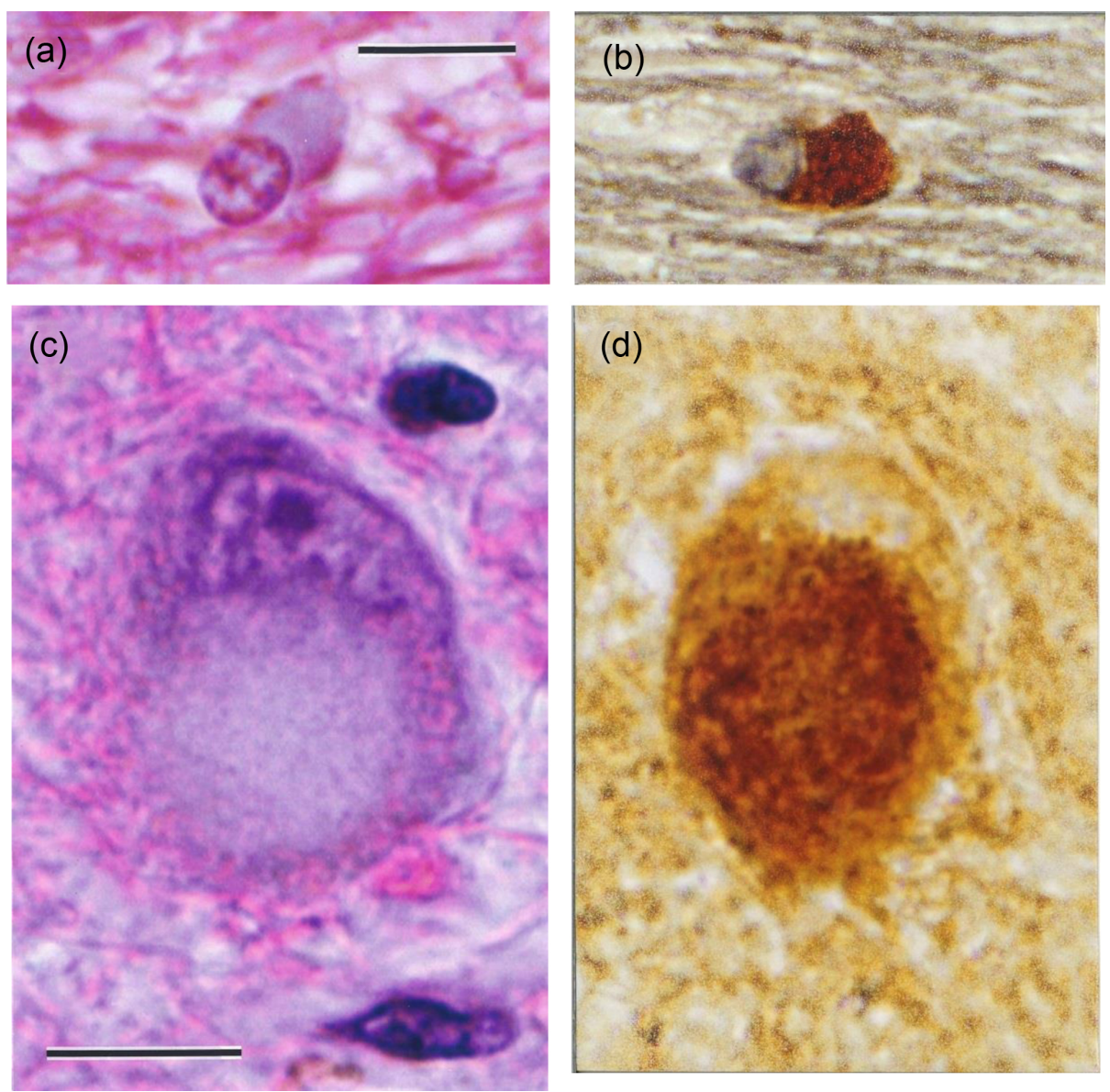

Figure 3. Glial cytoplasmic inclusion (GCI) and neuronal cytoplasmic inclusion (NCI) in patients with MSA-C. (a). H\&E staining in a patient with MSA-C. GCI appears pale structure. (b). CD3- $\varepsilon$-epitope immunostaining in a patient with MSA-C. GCI is strongly positive for CD3 $\varepsilon$ epitope. (c). H\&E staining in a patient with MSA-C. NCI is relatively demarcated and appears pale. The nucleus is displaced to the cellular periphery. (d). CD3- $\varepsilon$-epitope immunostaining in a patient with MSA-C. NCI is intensively recognized by immunostaining using antibody against CD3 $\varepsilon$ epitope. Figures $3(\mathrm{a})-(\mathrm{d})$ (same magnification as Figure 3 (a) and Figure 3(c)): Scale bars $=10 \mu \mathrm{m}$.

patients and their disease duration revealed the following facts: in the early stages of MSA-C, CD3- $\varepsilon$-epitope expression was lost from the tertiary dendrites, which are the most peripheral of the dendritic processes. As the disease progressed, CD3- $\varepsilon$-epitope expression was next lost from the secondary dendrites and then from the primary dendrites, finally disappearing off the cell bodies of the residual Purkinje cells. When humans contract MSA-C, the Purkinje cells are affected by so-called "MSA-C stress," the pathogenesis of which remains unknown. The functional and morphological damage to the Purkinje cells caused by this MSA-C stress starts at the periphery of the dendritic processes. The degeneration damage goes on to the primary dendrites, which form the trunks of the dendritic processes, and eventually MSA-C stress extends to the cell bodies that comprise the central part of Purkinje cells. Namely, the degeneration impairment of Purkinje cells affected by MSA-C stress occurs first at the periphery of the 

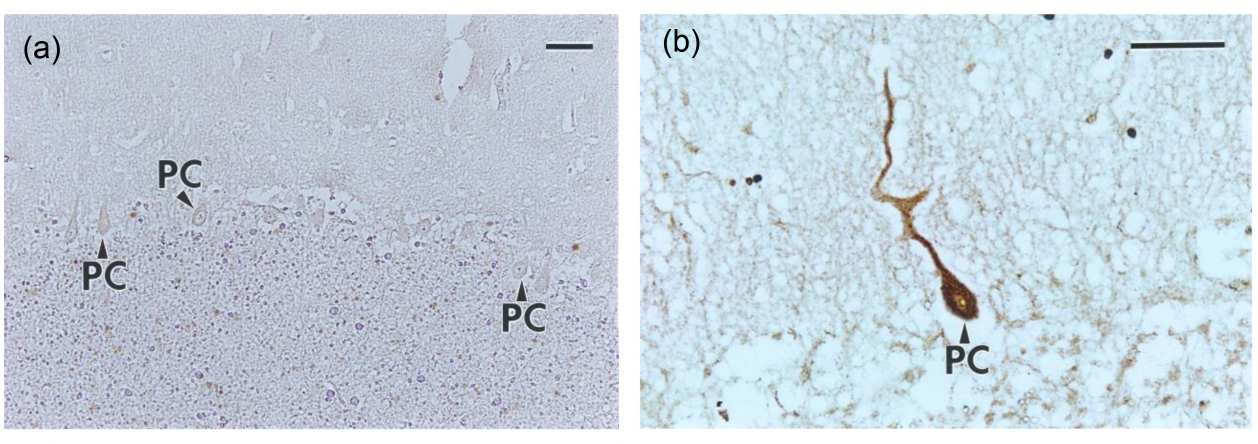

(c)

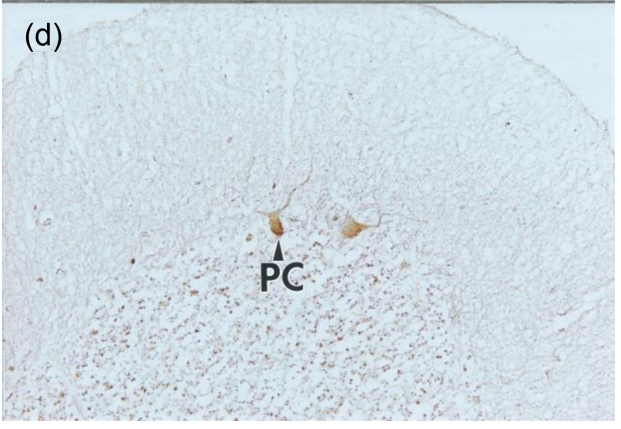

Figure 4. Immunostaining with antibody against oxidative modification to cysteine sulfonic acid of cys $^{111}$ in human copper-zinc superoxide dismutase (Ox-SOD1) in human cerebellar Purkinje cells from a normal individual and patients with MSA-C. (a). Immunostaining with antibody against Ox-SOD1 in human cerebellar Purkinje cells from a normal individual. Normal Purkinje cells (arrowhead and PC) are not stained by antibody against Ox-SOD1. (b). Immunostaining with antibody against Ox-SOD1 in a patient with MSA-C after a clinical course of 3 years. A residual Purkinje cell (arrowhead and PC) is positive for Ox-SOD1: cell body and major dendrites express Ox-SOD1. (c). Immunostaining with antibody against Ox-SOD1 in a patient with MSA-C after a clinical course of 4 years. Remaining Purkinje cells (arrowhead and PC) express Ox-SOD1 and some torpedes (arrowhead and tp) also express Ox-SOD1. (d). Immunostaining with antibody against Ox-SOD1 in a patient with MSA-C after a clinical course of 8 years. Surviving Purkinje cells (arrowhead and PC) are positive for Ox-SOD1. Figure 4(a), Figure 4(c) and Figure 4(d) (same magnification as Figure 4(a)): Scale bar $=50 \mu \mathrm{m}$ and Figure 4(b): Scale bar $=$ $50 \mu \mathrm{m}$.

dendritic processes and extends toward the cell body as the center of the Purkinje cell system.

In the normal developmental process of Purkinje cells from the fetal period through infancy and childhood to adulthood, the $\mathrm{CD} 3 \varepsilon$ epitope first appears in the Purkinje cell body (as the center of the cell system) at 21 weeks gestation. As normal development proceeds, it is expressed first in the primary dendrites, which form the trunks of the dendritic processes, and then in the secondary and the tertiary dendrites in that order [16]. Based on the fact that the functions of $\mathrm{CD} 3 \varepsilon$ epitope in human cerebellar Purkinje cell are involved with morphogenesis and morphological maintenance of normal developmental stage of Purkinje cells [16], the MSA-C Purkinje cells are considered to be impaired from the peripheral dendrites toward the cell bodies as the center of the Purkinje cell system: the degeneration process in the MSA-C Purkinje cells is the opposite process to that of the normal development. 
Cytosolic copper-zinc superoxide dismutase (SOD1) is the most symbolic and typical antioxidant defense enzyme, which eliminates free radicals that cause Purkinje cell damage: SOD1 prevents Purkinje cell damage from free radicals [8] [19] [20]. This is the first report that the surviving Purkinje cells in MSA-C patients expressed Ox-SOD1: even SOD1 in the MSA-C Purkinje cells is itself in a strongly-oxidized state.

Taken into the consideration that normal Purkinje cells did not express Ox-SOD1, the oxidative stress could be involved as one cause of the degeneration of Purkinje cells: one of the pathogeneses of MSA-C stresses is an oxidative stress.

The accumulation of $\alpha$-synuclein is considered to be one of pathogeneses in MSA-C [1]. This consideration is based on the fact that $\alpha$-synuclein accumulates in glial cytoplasmic inclusions (GCIs) [1] [21] and neuronal cytoplasmic inclusions (NCIs) [1] [22]. GCIs and NCIs have been considered histological hallmarks of MSA [1] [21] [22]. In addition, MSA is characterized by neuronal loss, astrocytosis, and myelin pallor; the most severe lesions are found in the cerebellar Purkinje cells. As for the pathogenesis of the myelin pallor in MSA, GCIs are thought to play a significant role, and the formation of these GCIs may be the crucial event through which the oligodendroglia-myelin-axon pathology causes neurodegeneration [23] [24] [25]. This hypothesis may be supported by the reports about the widespread myelin degeneration in MSA [26] and the loss of myelinated large fibers in corticopontine tracts [27]. In addition, the oligodendrocyte-myelin-axon-neuron relationship pathology would cause the neuronal death [23].

Together with the possibility that $\alpha$-synuclein could act as an important factor on the basis of aggregation toxicity, we discuss new findings that GCIs and NCIs were strongly positive for the $\mathrm{CD} 3 \varepsilon$ epitope. When oligodendrocytes are affected by $\alpha$-synucleinopathy, their morphogenesis is hypothesized to be damaged and the oligodendrocytes begin to degenerate. In response to the degeneration stress, the oligodendrocytes could upregulate the $\mathrm{CD} 3 \varepsilon$ epitope as a repair factor for morphological maintenance and morphogenesis. As a result, the upregulated $\mathrm{CD} 3 \varepsilon$ epitope is sequestered into the inclusions together with $\alpha$-synuclein. This causes the specific staining in GCIs for the CD3 $\varepsilon$-epitope. Through the oligodendrocyte-myelin-axon-neuron relationship, $\alpha$ synucleinopathy stress on neurons causes NCIs to form. Since the same pathological process as GCIs could apply to NCIs, NCIs were also intensively positive for CD3 $\varepsilon$ epitope. However, the relationship between the inclusion formation and the intense oxidative stress remains to be unknown.

\section{Conclusion}

We have showed that the surviving Purkinje cells in patients with MSA-C are subject to severe oxidative stress by using the antibody to Ox-SOD1. We have discovered that the MSA-C Purkinje cells are impaired from the peripheral dendrites toward the cell bodies as the center of the Purkinje cell system by using the antibody against CD3 $\varepsilon$ epitope: the functional impairment of morphogenesis and morphological maintenance related to CD3-E-epitope expression of the MSA-C Purkinje cells follows the opposite order to 
that of the normal development. We have also demonstrated that the antibody against CD3 $\varepsilon$ epitope specifically recognizes GCIs and NCIs, which are pathological hallmarks of MSA.

\section{Acknowledgements}

This study was supported in part by a Budget for Promoting Priority Measures in Discretionary Funds of the President in Tottori University (S.K.) and a Grant-in-Aid for Research on Rare and Intractable Diseases, the Research Committee on Establishment of Novel Treatments for Amyotrophic Lateral Sclerosis from Japan Agency for Medical Research and Development (S.K.), as well as a Budget for Development of Research Seeds in Tottori University Hospital (M.K.).

\section{Conflict of Interest}

All the authors declare that there is no conflict of interest.

\section{Funding}

None.

\section{References}

[1] Holton, J.L., Lees, A.J. and Revesz, T. (2011) Multiple System Atrophy. In: Dickson, D.W. and Weller, R.O., Eds., Neurodegeneration: The Molecular Pathology of Dementia and Movement Disorders, 2nd Edition, Wiley-Blackwell, Oxford, 242-252.

http://dx.doi.org/10.1002/9781444341256.ch24

[2] Fujisawa, K. and Nakamura, A. (1982) The Human Purkinje Cells. A Golgi Study in Pathology. Acta Neuropathologica, 56, 255-264.

http://dx.doi.org/10.1007/BF00691256

[3] Miyata, M., Miyata, H., Mikoshiba, K. and Ohama, E. (1999) Development of Purkinje Cells in Humans: An Immunohistochemical Study Using a Monoclonal Antibody against the Inositol 1, 4, 5-Triphosphate Type 1 Receptor (IP $\left.{ }_{3} \mathrm{R} 1\right)$. Acta Neuropathologica, 98, 226-232. http://dx.doi.org/10.1007/s004010051073

[4] Isumi, H., Mizuguchi, M. and Takashima, S. (1997) Differential Development of the Human Cerebellar Vermis: Immunohistochemical and Morphometrical Evaluation. Brain and Development, 19, 254-257. http://dx.doi.org/10.1016/S0387-7604(97)00570-6

[5] Nag, T.C. and Wadhwa, S. (1999) Calbindin Immunoreactivity in the Developing and Adult Human Cerebellum. Journal of Chemical Neuroanatomy, 17, 1-12. http://dx.doi.org/10.1016/S0891-0618(99)00016-2

[6] Koo, H. and Choi, B.H. (2001) Expression of Glial Cell Line-Derived Neurotrophic Factor (GDNF) in the Developing Human Fetal Brain. International Journal of Developmental Neuroscience, 19, 549-558. http://dx.doi.org/10.1016/S0736-5748(01)00042-9

[7] Arai, Y., Ijuin, T., Itoh, M., Takenawa, T., Takashima, S. and Becker, L.E. (2001) Developmental Changes of Synaptojanin Expression in the Human Cerebrum and Cerebellum. Developmental Brain Research, 129, 1-9. http://dx.doi.org/10.1016/S0165-3806(01)00140-7

[8] Yokoyama, A., Ohno, K., Hirano, A., Shintaku, M., Kato, M., Hayashi, K. and Kato, S. (2014) Cerebellar Expression of Copper Chaperone for Superoxide, Cytosolic Cu/Zn-Su- 
peroxide Dismutase, 4-Hydroxy-2-Nonenal, Acrolein and Heat Shock Protein 32 in Patients with Menkes Kinky Hair Disease: Immunohistochemical Study. Yonago Acta Medica, 57, 23-35.

[9] Kato, S., Ito, M., Ohama, E., Mikoshiba, K., Maeda, N., Yen, S.H., Hirano, A., Herz, F. and Shintaku, M. (1993) Immunohistochemical Studies on Cerebellar Purkinje Cells of Patients with Menkes' Kinky Hair Disease. Neuropathology, 13, 159-166.

http://dx.doi.org/10.1111/j.1440-1789.1993.tb00227.x

[10] Kato, S., Ito, M., Ohama, E., Mikoshiba, K., Maeda, N. and Hirano, A. (1993) Immunohistochemical Investigations on Cerebellar Purkinje Cells of Menkes' Kinky Hair Disease: Disappearance of Inositol 1, 4, 5-Triphosphate Receptor Protein, and Expression of Phosphorylated Neurofilament Proteins, $\alpha$ B-Crystallin and Stress-Response Proteins. Neuropathology, 13, 305-309. http://dx.doi.org/10.1111/j.1440-1789.1993.tb00213.x

[11] Kato, S., Hayashi, H., Mikoshiba, K., Hirano, A., Yen, S.H. and Ohama, E. (1998) Purkinje Cells in Olivopontocerebellar Atrophy and Granule Cell-Type Cerebellar Degeneration: An Immunohistochemical Study. Acta Neuropathologica, 96, 67-74. http://dx.doi.org/10.1007/s004010050861

[12] Meng, S.Z., Oka, A. and Takashima, S. (1999) Developmental Expression of Monocyte Chemoattractant Protein-1 in the Human Cerebellum and Brainstem. Brain Development, 21, 30-35. http://dx.doi.org/10.1016/S0387-7604(98)00065-5

[13] Royds, J.A., Ironside, J.W., Warnaar, S.O., Taylor, C.B. and Timperley, W.R. (1987) Monoclonal Antibody to Aldolase C: A Selective Marker for Purkinje Cells in the Human Cerebellum. Neuropathology and Applied Neurobiology, 13, 11-21. http://dx.doi.org/10.1111/j.1365-2990.1987.tb00167.x

[14] Sommers, C.L., Dejarnette, J.B., Huang, K., Lee, J., El-Khoury, D., Shores, E.W. and Love, P.E. (2000) Function of CD3 Epsilon-Mediated Signals in T Cell Development. Journal of Experimental Medicine, 192, 913-919. http://dx.doi.org/10.1084/jem.192.6.913

[15] Garson, J.A., Beverley, P.C.L., Coakham, H.B. and Harper, E.I. (1982) Monoclonal Antibodies against Human T Lymphocytes Label Purkinje Neurones of Many Species. Nature, 298, 375-377. http://dx.doi.org/10.1038/298375a0

[16] Kato, M., Hayashi, K., Kato, S., Kuwamoto, S. and Horie, Y. (2016) Development Expression of CD3 $\varepsilon$ Epitope in the Human Cerebellar Purkinje Cells from Fetuses, Neonates, Infants to Adults: An Immunohistochemical Study. Annals of Clinical Pathology, 4, 1082.

[17] Nakamura, K., Hirai, H., Torashima, T., Miyazaki, T., Tsurui, H., Xiu, Y., Ohtsuji, M., Lin, Q.S., Tsukamoto, K., Nishimura, H., Ono, M., Watanabe, M. and Hirose, S. (2007) CD3 and Immunoglobulin G Fc Receptor Regulate Cerebellar Functions. Molecular and Cellular Biology, 27, 5128-5134. http://dx.doi.org/10.1128/MCB.01072-06

[18] Fujiwara, N., Nakano, M., Kato, S., Yoshihara, D., Ookawara, T., Eguchi, H., Taniguchi, N. and Suzuki, K. (2007) Oxidative Modification to Cysteine Sulfonic acid of Cys111 in Human Copper-Zinc Superoxide Dismutase. The Journal of Biological Chemistry, 282, 3593335944. http://dx.doi.org/10.1074/jbc.M702941200

[19] Fridovich, I. (1986) Superoxide Dismutases. Advances in Enxymology and Related Areas of Molecular Biology, 58, 61-97. http://dx.doi.org/10.1002/9780470123041.ch2

[20] Kato, S., Takikawa, M., Nakashima, K., Hirano, A., Cleveland, D.W., Kusaka, H., Shibata, N., Kato, M., Nakano, I. and Ohama, E. (2000) New Consensus Research on Neuropathological Aspects of Familial Amyotrophic Lateral Sclerosis with Superoxide Dismutase 1 (SOD1) Gene Mutations: Inclusions Containing SOD1 in Neurons and Astrocytes. Amyotrophic Lateral Sclerosis Other Motor Neuron Disorders, 1, 163-184. http://dx.doi.org/10.1080/14660820050515160 
[21] Papp, M.I., Kahnm, J.E. and Lantos, P.L. (1989) Glial Cytoplasmic Inclusions in the CNS of Patients with Multiple System Atrophy (Striatonigral Degeneration, Olivopontocerebellar Atrophy and Shy-Drager Syndrome). Journal of Neurological Science, 94, 79-100. http://dx.doi.org/10.1016/0022-510X(89)90219-0

[22] Kato, S. and Nakamura, H. (1990) Cytoplasmic Argyrophilic Inclusions in Neurons of Pontine Nuclei in Patients with Olivopontocerebellar Atrophy: Immunohistochemical and U1trastructural Studies. Acta Neuropathologica, 79, 584-594.

http://dx.doi.org/10.1007/BF00294235

[23] Kato, S., Shinozawa, T., Takikawa, M., Kato, M., Hirano, A., Awaya, A. and Ohama, E. (2000) Midkine, A New Neurotrophic Factor, Is Present in Glial Cytoplasmic Inclusions of Multiple System Atrophy Brains. Acta Neuropathologica, 100, 481-489. http://dx.doi.org/10.1007/s004010000214

[24] Castellani, R. (1998) Multiple System Atrophy Clues from Inclusions. American Journal of Pathology, 153, 671-676. http://dx.doi.org/10.1016/S0002-9440(10)65608-8

[25] Lantos, P.L. (1998) The Definition of Multiple System Atrophy: A Review of Recent Developments. Journal of Neuropathology and Experimental Neurology, 57, 1099-1111. http://dx.doi.org/10.1097/00005072-199812000-00001

[26] Matsuo, A., Akiguchi, I., Lee, G.C., McGeer, E.G., Mc Geer, P.L. and Kimura, J. (1998) Myelin Degeneration in Multiple System Atrophy Detected by Unique Antibodies. American Journal of Pathology, 153, 735-744. http://dx.doi.org/10.1016/S0002-9440(10)65617-9

[27] Yagishita, S., Yokoi, S., Iwabuchi, K., Amano, N., Mashuda, Y., Hasegawa, K. and Kohwa, H. (1991) Degeneration of the Coricopontine Tract in Olivopontocerebellar Atrophy. Virchows Archiv A, 418, 99-103. http://dx.doi.org/10.1007/BF01600284

\section{Submit or recommend next manuscript to SCIRP and we will provide best service} for you:

Accepting pre-submission inquiries through Email, Facebook, LinkedIn, Twitter, etc.

A wide selection of journals (inclusive of 9 subjects, more than 200 journals)

Providing 24-hour high-quality service

User-friendly online submission system

Fair and swift peer-review system

Efficient typesetting and proofreading procedure

Display of the result of downloads and visits, as well as the number of cited articles

Maximum dissemination of your research work

Submit your manuscript at: http://papersubmission.scirp.org/

Or contactwjns@scirp.org 